\title{
SELECTIVE FEEDING OF TWO BIVALVE SPECIES ON THE PHYTOPLANKTON COMMUNITY IN AN AQUACULTURE POND REVEALED BY HIGH-THROUGHPUT SEQUENCING
}

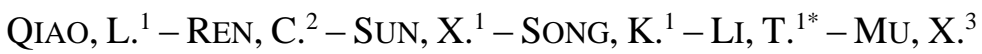 \\ ${ }^{1}$ Key Laboratory of Sustainable Utilization of Technology Research for Fishery Resource of \\ Zhejiang Province, Zhejiang Marine Fisheries Research Institute, Zhoushan 316012, China \\ ${ }^{2}$ Marine Science and Technology College, Zhejiang Ocean University, Zhoushan, Zhejiang \\ 316000, China \\ ${ }^{3}$ Fishery Resource and Environment Research Center, Chinese Academy of Fishery Sciences, \\ Beijing 100141, China \\ *Corresponding author \\ e-mail: litiejun1982@126.com; phone: +86-580-2299-886
}

(Received 26 $6^{\text {th }}$ May 2021; accepted $3^{\text {rd }}$ Sep 2021)

\begin{abstract}
Filtering bivalves consume microalgae throughout their life cycles, and for several decades, the selective feeding of bivalves on phytoplankton has been an active area of research in the fields of bivalve physiology and ecology. However, owing to the limitations of detection methods, there is comparatively little data available regarding the in situ food composition of suspension-feeding bivalves. In this study, conducted in December 2020, we used high-throughput sequencing of the 23S rRNA gene to characterize the phytoplankton community within the gut contents of the bivalves Meretrix meretrix and Scapharca subcrenata reared in the same aquaculture ponds. Phytoplankton from six phyla were identified in hepatopancreas samples obtained from M. meretrix, among which, Cyanophyta was found to be the predominant group, followed by Bacillariophyta. Seven phyla of phytoplankton were detected in the hepatopancreas samples obtained from S. subcrenata, among which, Cyanophyta and Chlorophyta were dominant. Ivlev's electivity index was used to evaluate the feeding selectivity of the bivalves. The results indicated that M. meretrix showed a preferential selection for Cyanophyta and Bacillariophyta, whereas $S$. subcrenata preferentially selected Xanthophyta, Cyanophyta, and Chlorophyta. At the genus level, $M$. meretrix showed a preference for 12 genera, including Phormidium, Pleurocapsa, Skeletonema, Synechococcus, and Planktothricoides, whereas S. subcrenata showed a preferential selection for 16 genera, including Tetraselmis, Pleurocapsa, and Planktothricoides.
\end{abstract}

Keywords: mariculture, Meretrix meretrix, Scapharca subcrenata, 23S rRNA gene, feeding selectivity

\section{Introduction}

Bivalves are the predominant mariculture species in China (Mao et al., 2019), with bivalve production in 2019 amounting to approximately 14.39 million tons, which accounted for more than 69\% of China's total mariculture production (CFSY, 2020). Bivalves not only affect phytoplankton community structure but also enhance sediment nutrient cycling via benthic-pelagic coupling (Newell, 2004; Smyth et al., 2013; Murphy et al., 2016), and accordingly play key functional roles in aquatic ecosystems. Bivalves can exert "top-down" grazer control on phytoplankton and filter other organic matter, thereby increasing the amount of light reaching the sediment surface, which in turn has the effect of reducing the dominance of phytoplankton production and extending the depth to which ecologically important benthic plants such as benthic microalgae can grow (Newell and Ott, 1999; Newell, 2004). Conversely, bivalves can also exert "bottom-up" nutrient control on phytoplankton production. The nitrogen and 
phosphorus excreted by bivalves and regenerated from their biodeposits are recycled back into the water column, thereby supporting further phytoplankton production (Newell, 2004). Given their ecological and economic importance, suspension-feeding bivalves have been extensively studied.

Meretrix meretrix and Scapharca subcrenata are important commercial bivalve species consumed in China (CFSY, 2020), for which live microalgae are a fundamental food source. In this regard, previous studies have revealed that bivalves are characterized by feeding selectivity (Ward and Shumway, 2004; Rosa et al., 2018). Certain bivalves have been found to distinguish their food from various types of particles, preferentially ingesting particles of a suitable size and nutrient content, while rejecting low-quality or unwanted material, thus optimizing energy intake (Ward and Shumway, 2004). Elucidating the food preferences of suspension-feeding bivalves is essential for enhancing existing models of bivalve growth and, consequently, to gain a better understanding of the dynamics of the ecosystems they dominate (Pales Espinosa et al., 2016). Accordingly, the mechanisms used by suspension-feeding bivalves to capture and ingest high-quality food from a mixture of particles of various sizes and physicochemical properties have for several decades been a major area of biological oceanographic research (Ward and Shumway, 2004; Rosa et al., 2018).

Several methodological approaches, including microscopic examination, pigmentbased method, isotope labeling method, real-time fluorescent quantitative PCR (qPCR), have been adopted for assessing the selective feeding of bivalves (Ward and Shumway, 2004; Rosa et al., 2018). In addition to being highly laborious and time-consuming, direct microscopy rarely enables accurate identification of similar taxa and small cells (Manoylov, 2014). In particular, food contents are often partially digested and morphologically altered, which accordingly hinders the acquisition of relevant information in the case of gut analyses (Sautour et al., 2000). Furthermore, pigmentbased methods are notably sensitive to pigment breakdown, and chlorophyll pigments tend to be broadly class-specific rather than specific to particular species (Irigoien et al., 2004). In addition, pigment-based methods do not yield data for heterotrophic prey (Nejstgaard et al., 2008). Although the aforementioned two methods can be used in in situ studies, investigations of the selective feeding of bivalves have been hampered by the inaccurate and laborious identification and counting of microalgal species. Although isotopic labeling has been used to provide information on the feeding preferences of bivalves (Brillant and MacDonald, 2002; Fukumori et al., 2008), this technique is both a time-consuming and expensive approach to distinguishing microalgal species. Moreover, the use of stable isotope tracers does not precisely reflect the in situ food composition of predators in the natural environment (Schmidt et al., 2003). qPCR has the notable advantages of strong specificity, high sensitivity, good repeatability, and accuracy, and has been successfully applied to assess the selective feeding of bivalve larvae based on species-specific primers targeting microalgal 18S rDNA sequences (Liao et al., 2017). This technique is mainly used for qualitative and quantitative detection of known bait microalgae, which although suitable for ingestion experiments in the laboratory, cannot be effectively applied in characterizing the diets of bivalves in the natural environment. Consequently, the prevailing lack of information regarding in situ diets can largely be attributed to methodological deficiencies that have hindered our understanding of the selective feeding of bivalves. Nevertheless, in recent years, the rapid development of modern molecular biological techniques has offered new approaches for examining the in situ food composition of organisms (Jedlicka et al., 
2017; Su et al., 2018). High-throughput sequencing is now more rapid, has higher throughput, is less costly, and has obvious advantages over the traditional methods of studying in situ bivalve diets.

In this study, we performed high-throughput sequencing of the 23S rRNA gene to investigate the composition of phytoplankton in the hepatopancreases of $M$. meretrix and $S$. subcrenata reared in aquaculture ponds, along with samples of pond water and sediments. The objectives of this study were to analyze the composition of phytoplankton within the gut contents of $M$. meretrix and S. subcrenata, and thereby characterize the feeding selectivity of these two bivalve species on phytoplankton in the natural environment.

\section{Materials and methods}

\section{Ethical statement}

All experiments conducted in this study were carried out in accordance with the Care and Use of Laboratory Animals guidelines formulated by the Ministry of Science and Technology of China. The protocol used in this study was approved by the Institutional Animal Care and Use Committee of Zhejiang Marine Fisheries Research Institute.

\section{Sample collection}

To examine the composition of phytoplankton potentially available as sources of food for the two bivalve species $M$. meretrix and $S$. subcrenata, we collected ambient four water samples and two sediment samples from two ponds at the Daishan Dongsha Aquafarm located in Zhoushan City, Zhejiang Province (30 $\left.18^{\prime} 50^{\prime \prime} \mathrm{N} ; 122^{\circ} 8^{\prime} 32^{\prime \prime} \mathrm{E}\right)$, in December 2020. Control samples were collected from an area of the ponds devoid of bivalves. Biological samples of $M$. meretrix and $S$. subcrenata were collected simultaneously and stored at $-4{ }^{\circ} \mathrm{C}$ for a short period of time prior to dissection.

\section{Sample preparation}

Samples of pond water $(1 \mathrm{~L})$ were filtered through $0.22 \mu \mathrm{m}$ Millipore membranes, and membranes containing the filtered plankton were flash frozen and stored at $-80{ }^{\circ} \mathrm{C}$ until used for DNA analysis. Sediment samples were sub-packaged into microtubes and stored at $-80{ }^{\circ} \mathrm{C}$ until used for DNA analysis. To reduce diet profile differences among the bivalve individuals, the hepatopancreases of 10 individuals were pooled as a single composite sample for each pond, homogenized with a pestle in $5 \mathrm{~mL}$ microtubes, and stored at $-80{ }^{\circ} \mathrm{C}$ until used for DNA analysis.

\section{High-throughput sequencing of phytoplankton and bioinformatic analysis}

Total genomic DNA was extracted from all samples using a FastDNA spin kit for soil (MP Biomedicals, OH, USA), following the manufacturer's instructions. The quality of the DNA was verified by gel electrophoresis on $0.5 \%$ agarose gels, and DNA concentrations were determined using a NanoDrop spectrophotometer (NanoDrop Technologies, Wilmington, DE, USA). The primers p23SrV_f1 (5'-GGA CAG AAA GAC CCT ATG AA-3') and p23SrV_r1 (5'-TCA GCC TGT TAT CCC TAG AG-3') were used to amplify the 23S rDNA gene (Sherwood and Presting, 2007). Purified PCR 
products were sequenced at Majorbio Bio-Pharm Technology Co. Ltd. (Shanghai, China) using the MiSeq platform (Illumina, San Diego, USA).

The 23S rDNA sequences were processed using the QIIME (version 1.91) software package. The original sequence data were sorted into valid reads after demultiplexing and quality filtering, and the high-quality sequences thus obtained were clustered into operational taxonomic units (OTUs) with an identity threshold of 97\%, using UPARSE (version $7.1 \mathrm{http}: / /$ drive 5.com/uparse/) with a novel "greedy" algorithm that performs simultaneous de novo-based chimera filtering and OTU clustering. The taxonomy of a representative sequence of each OTU was assigned using the Basic Local Alignment Search Tool (BLAST) in the NCBI database (http://www.ncbi.nlm.nih.gov). Following the exclusion of bacteria (all non-cyanobacteria) and unclassified sequences, phytoplankton sequences were selected for analysis of community composition based on taxonomic information.

The sequencing data used in this study have been archived in the Sequence Read Archive (SRA) of the NCBI database under accession number SRP307598.

\section{Feeding selectivity analysis}

The selectivity of bivalves with respect to feeding on phytoplankton was evaluated using Ivlev's electivity index (E) (Ivlev, 1961), calculated using the following formula:

$$
\mathrm{E}=\left(\mathrm{r}_{i}-\mathrm{p}_{i}\right) /\left(\mathrm{r}_{i}+\mathrm{p}_{i}\right)
$$

In Equation 1, $\mathrm{r}_{i}$ is the relative abundance of phytoplankton in the hepatopancreas sample from bivalves, and $\mathrm{p}_{i}$ is the relative abundance of similar items in pond water. The calculated values of $\mathrm{E}$ range from -1.0 to +1.0 , with $-1.0 \leq \mathrm{E} \leq-0.3$ indicating the avoidance or inaccessibility of a prey item, $-0.3<\mathrm{E}<0.3$ indicating random selection from the environment, and $0.3 \leq \mathrm{E} \leq 1.0$ indicating active selection (Strauss, 1979; Puig et al., 2001).

\section{Results}

\section{High-throughput sequencing data}

A total of 290,347 raw reads with an average read length of 368 nucleotides were obtained based on the high-throughput Illumina sequencing of all samples. After quality and chimera assessments and the removal of low-quality reads, a total of 263,314 clean reads and 334 OTUs were obtained (Table 1). Taxa were assigned to the representative sequences of each OTU using the NCBI database. On the basis of the taxonomic information thus obtained, the sequences were annotated to 20 different phyla (Fig. 1). In the control sample, Chrysophyta sequences accounted for the highest proportion of the total sequences $(54.86 \%)$, followed by Chlorophyta $(16.33 \%)$ and Cryptophyta $(11.15 \%)$. In water samples, Cryptophyta showed the highest relative abundance (41.49\%), followed by Chrysophyta $(26.69 \%)$ and Chlorophyta (14.06\%), whereas dominant phyla in the sediment samples were Cyanobacteria (56.88\%) and Bacillariophyta (30.08\%). In the hepatopancreas samples obtained from M. meretrix, Cyanobacteria (45.36\%), and Proteobacteria (11.28\%) were found to be dominant, whereas in samples obtained from S. subcrenata, Cyanobacteria (31.88\%), Chlorophyta (23.89\%), and Proteobacteria (13.67\%) were predominant (Fig. 1). Following the 
exclusion of bacteria (all non-cyanobacteria), zooplankton, macroalgae, and unclassified sequences, the remaining 216,910 sequences were assigned to the phytoplankton taxa (Table 1). The number of phytoplankton sequences was randomly rarefied to the number of sequences present in the sample with the lowest amount, which was used in further analyses of community composition and diversity.

Table 1. The numbers of sequences in quality control analysis

\begin{tabular}{c|c|c|c|c}
\hline Samples & $\begin{array}{c}\text { Raw } \\
\text { reads }\end{array}$ & $\begin{array}{c}\text { Clean } \\
\text { reads }\end{array}$ & $\begin{array}{c}\text { Total } \\
\text { OTUs }\end{array}$ & $\begin{array}{c}\text { Phytoplankton } \\
\text { reads }\end{array}$ \\
\hline Control sample & 62,630 & 54,962 & 152 & 52,716 \\
Water sample & 62,914 & 55,651 & 175 & 54,314 \\
Sediment sample & 64,269 & 55,506 & 219 & 51,362 \\
Hepatopancreas sample from Meretrix meretrix & 47,655 & 46,595 & 78 & 26,854 \\
Hepatopancreas sample from Scapharca subcrenata & 52,879 & 50,602 & 87 & 31,665 \\
Sum & 290,347 & 263,314 & 334 & 216,910 \\
\hline
\end{tabular}

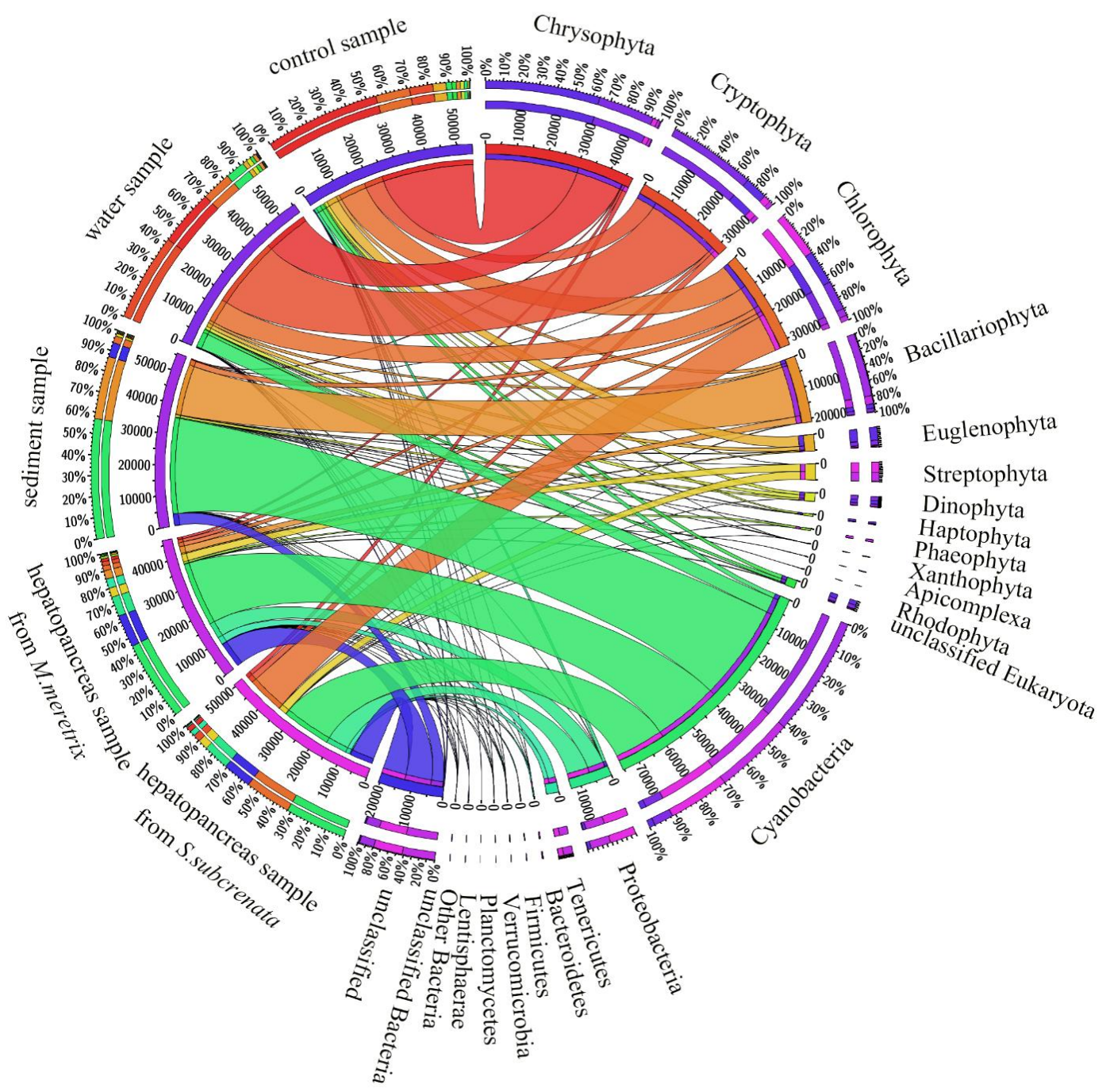

Figure 1. Circular representation of sequences assigned to 20 phyla and unclassified groups of phytoplankton 


\section{Phytoplankton community composition}

At the phylum level, we identified a total of nine phyla based on high-throughput sequencing, namely, Cyanophyta, Chrysophyta, Chlorophyta, Cryptophyta, Bacillariophyta, Euglenophyta, Dinophyta, Haptophyta, and Xanthophyta (Fig. 2a). In the control sample, Chrysophyta was found to be the predominant group, accounting for $57.48 \%$ of the total phytoplankton community, followed by Chlorophyta (16.96\%) and Cryptophyta $(11.53 \%)$. In the water samples, Cryptophyta showed the highest relative abundance (46.00\%), followed by Chrysophyta (25.39\%) and Chlorophyta (14.21\%), and in the sediment samples, Cyanophyta and Bacillariophyta comprised the largest proportions of phytoplankton, with relative abundances of $62.26 \%$ and $31.65 \%$, respectively. No representatives of Xanthophyta were detected in sediment samples. In the hepatopancreas samples obtained from $M$. meretrix, only six phyla were identified, with Cyanophyta being the predominant group (76.36\%), followed by Bacillariophyta $(8.71 \%)$. No representatives of the phyla Dinophyta, Haptophyta, and Xanthophyta were detected in these samples. Seven phyla (excluding Euglenophyta and Haptophyta) were detected in the hepatopancreas samples of S. subcrenata, with Cyanophyta (60.22\%) and Chlorophyta (32.08\%) being characterized as the most prominent groups.

At the genus level, we identified 57 genera based on high-throughput sequencing. In the control sample, Pseudopedinella was found to be the predominant group, accounting for $57.34 \%$ of the total phytoplankton, followed by Ostreococcus $(13.37 \%)$. In the water samples, Teleaulax and Pseudopedinella represented the largest proportions of phytoplankton, with relative abundances of $43.48 \%$ and $25.28 \%$, respectively, whereas large proportions of Synechococcus $(55.52 \%)$ and Skeletonema $(18.89 \%)$ were present in the sediment samples. In the hepatopancreas samples obtained from $M$. meretrix, Synechococcus (40.53\%) and Phormidium (16.47\%) were the predominant genera, whereas large proportions of Planktothricoides, Tetraselmis, Pleurocapsa, and Synechococcus were detected in the hepatopancreas samples obtained from $S$. subcrenata, with relative abundances of $25.46 \%, 24.75 \%, 20.95 \%$, and $10.27 \%$, respectively (Fig. 2b).

\section{Feeding selectivity of bivalves}

The feeding selectivity of bivalves on phytoplankton was evaluated based on Ivlev's electivity index (Fig. 3). At the phylum level, the index values indicated that $M$. meretrix showed preferential selection for Cyanophyta (0.80) and Bacillariophyta (0.68), whereas it tends to avoid Dinophyta (-1.00), Haptophyta (-1.00), Xanthophyta ($1.00)$, Cryptophyta (-0.81), Chrysophyta (-0.77), and Chlorophyta (-0.44), and appears to consume Euglenophyta according to availability. Comparatively, S. subcrenata was found to preferentially select Xanthophyta (0.82), Cyanophyta (0.75), and Chlorophyta (0.39), but appeared to avoid Euglenophyta (-1.00), Haptophyta (-1.00), Dinophyta (0.92), Cryptophyta (-0.84), Chrysophyta (-0.79), and Bacillariophyta (-0.70). At the genus level, $M$. meretrix showed a preference for 12 genera and a neutral response to 28 genera (Table 2), whereas $S$. subcrenata showed a preferential selection for 16 genera but a neutral response to 27 genera (Table 2). Among the dominant genera in the samples (Fig. 2b), M. meretrix appears to actively select Phormidium (1.00), Pleurocapsa (0.98), Skeletonema (0.89), Synechococcus (0.68), Planktothricoides (0.48), and avoids Pseudopedinella (-1.00), Tetraselmis (-1.00), Ostreococcus (-1.00), and Teleaulax (-0.89). S. subcrenata actively selects Tetraselmis (1.00), Pleurocapsa 


$$
-4483-
$$

(0.99), Planktothricoides (0.99), and avoids Pseudopedinella (-1.00), Ostreococcus (1.00), Teleaulax (-0.88), and Skeletonema (-0.37), whereas Synechococcus is selected according to availability.

Table 2. Selectivity of Meretrix meretrix and Scapharca subcrenata for phytoplankton at the genus level. Symbols “+”, “-” and "/” indicates active selection, avoidance and random selection, respectively

\begin{tabular}{|c|c|c|}
\hline Genus & M. meretrix & S. subcrenata \\
\hline Synechococcus & + & 1 \\
\hline Pseudopedinella & - & - \\
\hline Teleaulax & - & - \\
\hline Pleurocapsa & + & + \\
\hline Skeletonema & + & - \\
\hline Planktothricoides & + & + \\
\hline Tetraselmis & - & + \\
\hline Ostreococcus & - & - \\
\hline Phormidium & + & I \\
\hline Eutreptiella & I & - \\
\hline Cyanobium & + & + \\
\hline Picochlorum & + & + \\
\hline Haslea & - & - \\
\hline Gloeotilopsis & + & + \\
\hline Microchloropsis & + & + \\
\hline Micromonas & - & - \\
\hline Halamphora & - & - \\
\hline Nostoc & + & - \\
\hline Kryptoperidinium & - & - \\
\hline Proteomonas & I & I \\
\hline Chrysochromulina & - & - \\
\hline Actinocyclus & - & - \\
\hline Synechocystis & + & + \\
\hline Lyngbya & - & + \\
\hline Microcoleus & + & I \\
\hline Pyramimonas & - & - \\
\hline Oscillatoria & I & + \\
\hline Anabaena & I & + \\
\hline Jaaginema & - & + \\
\hline Nitzschia & - & - \\
\hline Cyanobacterium & l & + \\
\hline Pseudoscourfieldia & - & / \\
\hline Bathycoccus & - & - \\
\hline Vaucheria & I & + \\
\hline Chondrocystis & I & + \\
\hline Lusitaniella & I & + \\
\hline Thermosynechococcus & - & - \\
\hline Trichodesmium & - & - \\
\hline Nephroselmis & - & - \\
\hline Heterosigma & - & - \\
\hline Marsupiomonas & - & - \\
\hline Picocystis & - & - \\
\hline Euglena & - & - \\
\hline Tisochrysis & - & - \\
\hline Mychonastes & - & - \\
\hline Spirulina & - & - \\
\hline Resultomonas & - & - \\
\hline Dangeardinia & - & - \\
\hline
\end{tabular}




$$
-4484 \text { - }
$$

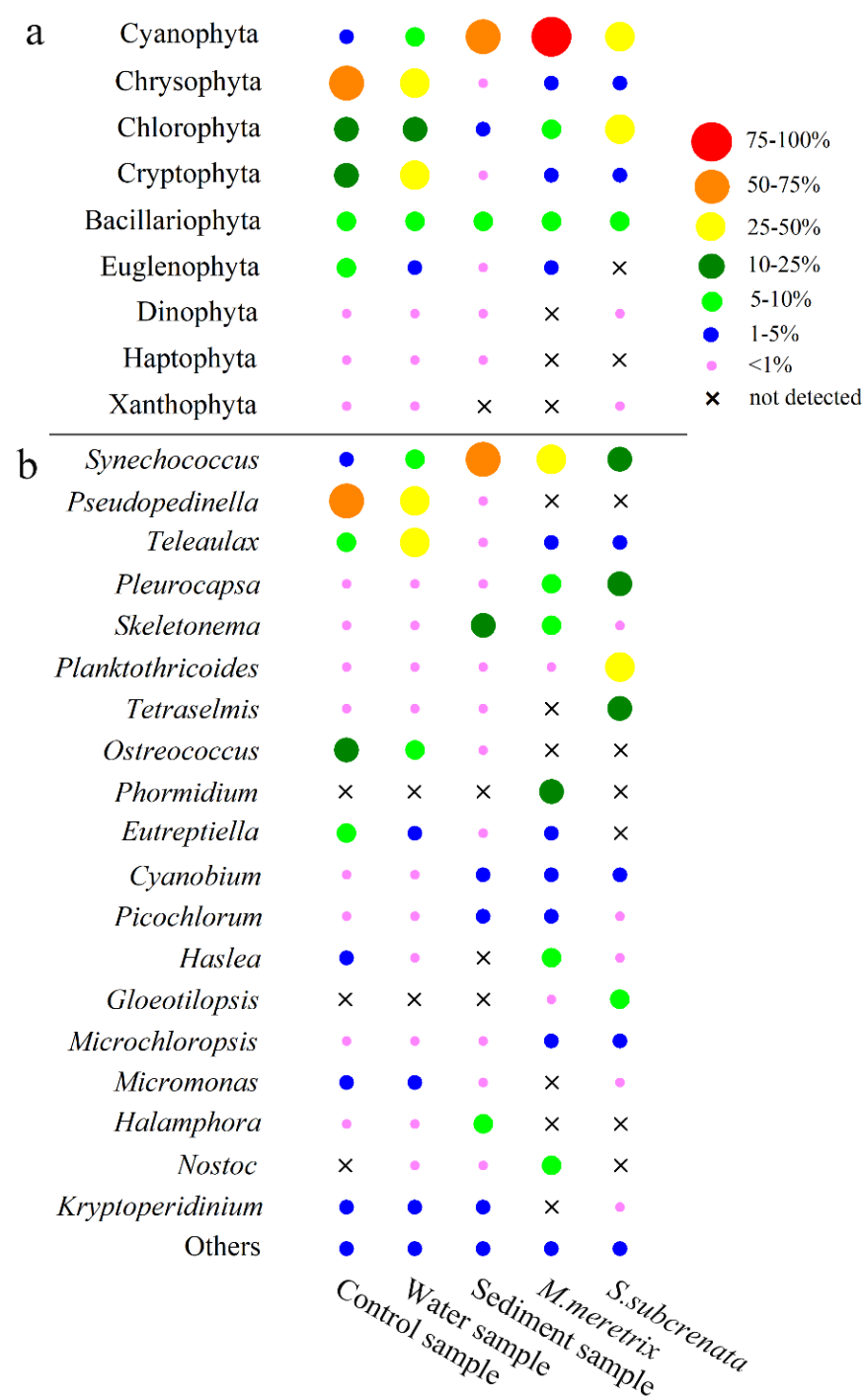

Figure 2. Relative abundance of taxa in the phytoplankton community at the phylum (a) and genus (b) levels identified using high-throughput sequencing. The size of the circles shows proportions of sequences from each sample
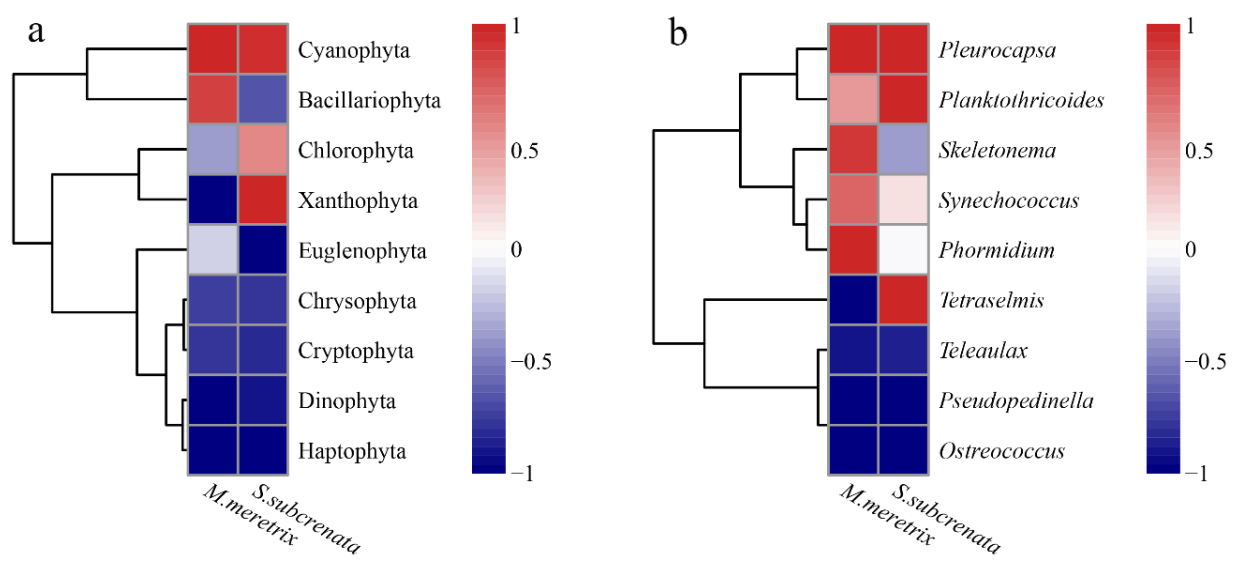

Figure 3. Heatmaps showing bivalve feeding selectivity on phytoplankton at the phylum (a) and genus (b) levels 


\section{Discussion}

During the course of their lifetime, bivalves feed exclusively on Phytoplankton, the availability of which is a key factor in determining growth and development, and is also an important factor affecting the sustainable development of aquaculture. The accuracy and precision of the methods used to analyze diets make an important contribution to theoretical studies of feeding, which is also vital to the application of research results in the practice of ecological aquaculture. In recent years, there have been notable advances with respect to the methodology used for dietary analyses (Leray et al., 2013; Leal et al., 2016; Hirai et al., 2017), with high-throughput sequencing being increasingly more widely used by researchers, given its high efficiency. A number of marker genes (including 16S rRNA, 18S rDNA, and ITS) have been employed to characterize the feeding habits and intestinal microbial communities of aquatic animals (Borsodi et al., 2017; Su et al., 2018; Yeh et al., 2020). The universal plastid amplicon (UPA), a fragment of the plastid 23S rRNA gene, can be used not only to eliminate the interference of bivalve host genes but also to identify both eukaryotic algae and cyanobacteria, which are widely used to study phytoplankton community structure and diversity (Sherwood and Presting, 2007; Li et al., 2016; Qiao et al., 2019). In the present study, we used sequences of the 23S rDNA gene as a marker, analyzed based Illumina sequencing, to assess the feeding preference of $M$. meretrix and $S$. subcrenata on phytoplankton in the same aquacultural ponds, knowledge of which is essential for gaining an understanding of aquatic food webs and facilitating the ecosystem-based management of aquaculture.

In this study, we identified six phytoplankton phyla in hepatopancreas samples obtained from M. meretrix (Fig. 2a), among which, Cyanophyta was found to be the predominant group, followed by Bacillariophyta. Comparatively, seven phyla were detected in the hepatopancreas of $S$. subcrenata, with Cyanophyta and Chlorophyta featuring predominantly (Fig. 2a). In this regard, previous studies of the gut contents of more than 200 bivalve species (Hunt, 1925; Nelson, 1927, 1947; Hillman, 1965) have indicated that diatoms constitute the primary food source of bivalves (Rosa et al., 2018). We speculate that the disparity between these findings and those of the present study could be attributable to differences in the detection methods used. A majority of the previous studies have tended to use traditional microscopic techniques, amongst which light microscopy has notable limitations with respect to the identification and classification of phytoplankton with small cell sizes, particularly pico-sized and some small nano-sized phytoplankton (Manoylov, 2014; Qiao et al., 2019). In the present study, we identified the two algal genera Synechococcus and Phormidium as being dominant in the hepatopancreas samples obtained from M. meretrix, the diameters of which have previously been determined as ranging from 0.6 to $2.1 \mu \mathrm{m}$ (Herdman et al., 2001) and 0.7 to $6.3 \mu \mathrm{m}$ (Marquardt and Palinska, 2007), respectively. In the hepatopancreas samples from $S$. subcrenata, we detected large proportions of the genera Planktothricoides, Tetraselmis, Pleurocapsa, and Synechococcus. Previous studies on the ultrastructure of Planktothricoides, Tetraselmis, and Pleurocapsa have shown that these three algal genera have respective length and width dimensions of 1.86 to $5.96 \mu \mathrm{m}$ and 2.83 to $13.70 \mu \mathrm{m} ; 6$ to $16 \mu \mathrm{m}$ and 4 to $10.5 \mu \mathrm{m}$; and $1.5 \mu \mathrm{m}$ and $0.2 \mu \mathrm{m}$ (Wujek, 1979; Hori et al., 1986; Tawong, 2017). Given these size ranges, these algae could easily evade detection by light microscopy. In recent years, an increasing number of studies have examined the contributions of picoplankton and other small particles $(<4 \mu \mathrm{m})$ to bivalve growth (LeBlanc et al., 2012; Strøhmeier et al., 2012; Sonier et al., 2016). These picoplankton are operationally defined as particles ranging in size from 
0.2 to $2 \mu \mathrm{m}$, among which are included cyanobacteria and small eukaryotes that can numerically dominate the seston (Rosa et al., 2018). Consequently, it is quite conceivable that the contribution of pico-sized and small nano-sized phytoplankton to bivalve energetics is notably higher than previously reported.

Different bivalves have been found to have differing feeding preferences (Rosa et al., 2018). For example, Shumway et al. (1985) have applied flow cytometric techniques (FCM) to study particle capture in Ostrea edulis and demonstrated that this species preferentially captures the dinoflagellate Prorocentrum minimum over a similarly sized diatom (Phaeodactylum tricornutum) and cryptophyte (Chroomonas salina). In juvenile scallops of three species (Placopecten magellanicus, Patinopecten yessoensis, and Argopecten irradians) simultaneously fed a total of six algal clones, clearance rates were monitored using FCM, the results of which indicated that in scallops fed natural assemblages of particles, clearance rates varied between species, with Placopecten generally having higher uptake rates for all three size classes of particles $(3-5 \mu \mathrm{m}, 5-$ $8 \mu \mathrm{m},>8 \mu \mathrm{m})$ followed by Argopecten and Patinopecten. For the $8-\mu \mathrm{m}$ size class of particles, Argopecten was found to have the highest clearance rate (Shumway et al., 1997). In laboratory feeding experiments conducted by Tang et al. (2006), of the authors provided $M$. meretrix with five different species of marine microalgae (Isochrysis galbana, Dunaliella sp., Phaeodactylum tricornutum, Platymonas subcordiformis, and Pavlova viridis), both singly and in various mixtures, and accordingly found that the larvae of this bivalve were characterized by selective feeding behavior, with a preference for I. galbana. In the present study, we found that $M$. meretrix showed a clear preference for Cyanophyta (Phormidium, Pleurocapsa, Synechococcus) and Bacillariophyta (Skeletonema), whereas S. subcrenata preferentially selected Xanthophyta (Vaucheria), Cyanophyta (Pleurocapsa and Planktothricoides), and Chlorophyta (Tetraselmis) (Fig. 3; Table 2).

The selective feeding of bivalves on phytoplankton is potentially associated with multiple factors, including cell size and shape and the quality, quantity, and availability of food (Tang et al., 2006; Chen et al., 2015; Rosa et al., 2013, 2015, 2018). Feeding selectivity based on particle size has been found to differ among bivalve species, and is probably dependent on bivalve ctenidial architecture and laterofrontal cilia/cirri microstructure (Rosa et al., 2018). In this regard, mussels have a filibranchiate homorhabdic ctenidium with large compound laterofrontal cirri that are highly efficient with respect to capturing particles ranging in size from $4 \mu \mathrm{m}$ to $10 \mu \mathrm{m}$ (Riisgård, 1988; Rosa et al., 2015, 2018). Compared with mussels, oysters have a pseudolamellibranchiate heterorhabdic ctenidium with well-developed laterofrontal cirri (Owen and McCrae, 1976; Ribelin and Collier, 1977), which generally have a higher capture efficiency for particles that are larger in size by more than $3 \mu \mathrm{m}$ (Rosa et al., 2018). Moreover, scallops have a filibranchiate heterorhabdic ctenidium with a single row of laterofrontal cilia (Owen and McCrae, 1976; Beninger, 1991) and have been reported to have low capture efficiency for 2-7 $\mu \mathrm{m}$ particles (Møhlenberg and Riisgård, 1978; Riisgård, 1988).

In addition to cell size, the feeding behavior of some bivalves might also be associated with a requirement for certain essential nutrients (Caers et al., 1999; Tang et al., 2006; Chen et al., 2015). For example, studies have shown that higher eicosapentaenoic acid and arachidonic acid levels in the diet appear to have a positive effect on the total hemocyte count, granulocyte percentage, phagocytic rate, oxidative activity, and immunity of bivalves (Delaporte et al., 2003, 2006). Microalgae commonly used as aquaculture feeds include Phormidium, Skeletonema, Thalassiosira, 
Tertraselmis, Pavlova, Isochrysis, and Nannochloropsis, which are noted for their high nutritional value, particularly their high contents of polyunsaturated fatty acids (MullerFeuga et al., 2003; Thajuddin and Subramanian, 2005). In addition, phytoplankton motility may influence the feeding preferences of bivalves. In the present study, we observed that both $M$. meretrix and $S$. subcrenata appeared to avoid consuming Pseudopedinella and Teleaulax (Fig. 3; Table 2), even though these two genera were predominant groups in the assessed water samples (Fig. 2b). The phytoplankton in these two genera are characterized by flagella, which play an important motility-related role by pulling cells in a forward direction (Heimann et al., 1989; Laza-Martínez et al., 2012; Gerea et al., 2016). This motility presumably enables the cells to evade capture by bivalves, and conceivably accounts for their higher relative abundance in water samples.

It should be noted that the findings of the present study are based on only a single sampling survey conducted on water samples and organisms collected from aquaculture ponds, and consequently, we have not been able to assess differences in the feeding selectivity of bivalves during different periods of aquaculture. Accordingly, it is necessary to carry out continuous monitoring surveys to examine differences in the feeding selectivity of different bivalve species during the different stages of culture. Nevertheless, the findings of this study do provide a useful foundation for future studies on the feeding selectivity of bivalves in natural environments using high-throughput sequencing technology.

\section{Conclusions}

In this study, we performed high-throughput sequencing to characterize the phytoplankton compositions of water and sediments and gut contents of the bivalves $M$. meretrix and $S$. subcrenata in samples collected from aquaculture ponds. In the water samples, we found Cryptophyta to have the highest relative abundance, followed by Chrysophyta and Chlorophyta, whereas in sediment samples, Cyanophyta and Bacillariophyta comprised a large proportion of the phytoplankton population. Phytoplankton within six phyla were identified in hepatopancreas samples obtained from M. meretrix, among which, Cyanophyta was found to be the predominant group, followed by Bacillariophyta. Similarly, we detected seven phyla of phytoplankton in hepatopancreas samples obtained from $S$. subcrenata, among which, Cyanophyta and Chlorophyta predominated. Using Ivlev's electivity index to evaluate the feeding selectivity of the two bivalve species, we established that $M$. meretrix preferentially selects phytoplankton within the phyla Cyanophyta and Bacillariophyta, whereas $S$. subcrenata was characterized by a preference for Xanthophyta, Cyanophyta, and Chlorophyta. At the genus level, M. meretrix showed a preference for 12 genera, including Phormidium, Pleurocapsa, Skeletonema, Synechococcus, and Planktothricoides, whereas $S$. subcrenata preferentially selects 16 genera, among which were Tetraselmis, Pleurocapsa, and Planktothricoides. In the future study, it is necessary to carry out continuous monitoring surveys to examine differences in the feeding selectivity of different bivalve species during the different stages of culture.

Acknowledgements. This study was supported by the Science and Technology Planning Project of Zhejiang Marine Fisheries Research Institute (HYS-ZY-202101), the Start-up Foundation for Doctors of Zhejiang Ocean University (11034150220004), and the Natural Science Foundation of Zhejiang Province (LQ20D030002). 


\section{REFERENCES}

[1] Beninger, P. G. (1991): Structures and Mechanisms of Feeding in Scallops: Paradigms and Paradoxes. - In: Shumway, S. E. (ed.) An International Compendium of Scallop Biology and Culture. Baton Rouge, LA, pp. 331-340.

[2] Borsodi, A. K., Szabó, A., Krett, G., Felfldi, T., Boros, G. (2017): Gut content microbiota of introduced bigheaded carps (Hypophthalmichthys spp.) inhabiting the largest shallow lake in Central Europe. - Microbiological Research 195: 40-50.

[3] Brillant, M., MacDonald, B. A. (2002): Postingestive selection in the sea scallop (Placopecten magellanicus) on the basis of chemical properties of particles. - Marine Biology 141(3): 457-465.

[4] Caers, M., Coutteau, P., Sorgeloos, P. (1999): Dietary impact of algal and artificial diets, fed at different feeding rations, on the growth and fatty acid composition of Tapes philippinarum (L.) spat. - Aquaculture 170(3): 307-322.

[5] CFSY (2020): China Fishery Statistical Yearbook. - China Agriculture Publishing House, Beijing.

[6] Chen, S. M., Tseng, K. Y., Huang, C. H. (2015): Fatty acid composition, sarcoplasmic reticular lipid oxidation, and immunity of hard clam (Meretrix lusoria) fed different dietary microalgae. - Fish and Shellfish Immunology 45(1): 141-145.

[7] Delaporte, M., Soudant, P., Moal, J., Lambert, C., Samain, J. F. (2003): Effect of a monospecific algal diet on immune functions in two bivalve species - Crassostrea gigas and Ruditapes philippinarum. - Journal of Experimental Biology 206(Pt 17): 3053-3064.

[8] Delaporte, M., Soudant, P., Moal, J., Giudicelli, E., Lambert, C., Séguineau, C., Samain, J. (2006): Impact of 20:4n-6 supplementation on the fatty acid composition and hemocyte parameters of the pacific oyster Crassostrea gigas. - Lipids 41: 567-576.

[9] Fukumori, K., Oi, M., Doi, H., Okuda, N., Yamaguchi, H., Kuwae, M., Miyasaka, H., Yoshino, K., Koizumi, Y., Omori, K., Takeoka, H. (2008): Food sources of the pearl oyster in coastal ecosystems of Japan: evidence from diet and stable isotope analysis. Estuarine Coastal and Shelf Science 76(3): 704-709.

[10] Gerea, M., Saad, J. F., Izaguirre, I., Queimalinos, C., Unrein, F. (2016): Presence, abundance and bacterivory of the mixotrophic algae Pseudopedinella (Dictyochophyceae) in freshwater environments. - Aquatic Microbial Ecology 76(3): 219-232.

[11] Heimann, K., Benting, J., Timmermann, S., Melkonian, M. (1989): The flagellar developmental cycle in algae: two types of flagellar development in uniflagellate algae. Protoplasma 153(1-2): 14-23.

[12] Herdman, H., Castenholz, R. W., Waterbury, J. B., Rippka, R. (2001): Form-Genus XIII. Synechococcus. - In: Boone, D. R., Castenholz, R. W. (eds.), Bergey's Manual of Systematic Bacteriology. Springer-Verlag, New York, pp. 508-512.

[13] Hillman, R. E. (1965): The American oyster, Crassostrea virginica gmelin. - Chesapeake Science 6: 199.

[14] Hirai, J., Hidaka, K., Nagai, S., Ichikawa, T. (2017): Molecular-based diet analysis of the early post-larvae of Japanese sardine Sardinops melanostictus and Pacific round herring Etrumeus teres. - Marine Ecology Progress 564(564): 99-113.

[15] Hori, T., Norris, R. E., Chihara, M. (1986): Studies on the ultrastructure and taxonomy of the Genustetraselmis (Prasinophyceae). - The Botanical Magazine, Tokyo 99(1): 123135.

[16] Hunt, O. D. (1925): The food of the bottom fauna of the Plymouth fishing grounds. Journal of the Marine Biological Association of the United Kingdom 13: 560-599.

[17] Irigoien, X., Meyer, B., Harris, R., Harbour, D. (2004): Using HPLC pigment analysis to investigate phytoplankton taxonomy: the importance of knowing your species. Helgoland Marine Research 58(2): 77-82. 
[18] Ivlev, V. S. (1961): Experimental Ecology of the Feeding of Fish. - Yale University Press New Haven, CT.

[19] Jedlicka, J., Vo, A., Almeida, R. (2017): Molecular scatology and high-throughput sequencing reveal predominately herbivorous insects in the diets of adult and nestling Western Bluebirds (Sialia mexicana) in California vineyards. - The Auk 134(1): 116127.

[20] Laza-Martínez, A., Arluzea, J., Miguel, I., Orive, E. (2012): Morphological and molecular characterization of Teleaulax gracilis $\mathrm{sp}$. nov. and T. minuta sp. nov. (Cryptophyceae). - Phycologia 36(1): 37-52.

[21] Leal, M. C., Ferrier-Pagès, C. (2016): Molecular trophic markers in marine food webs and their potential use for coral ecology. - Marine Genomics 29: 1-7.

[22] Leblanc, A., Arnold, A. A., Genard, B., Nadalini, J. B., Heine, M., Marcotte, I., Tremblay, R., Sleno, L. (2012): Determination of isotopic labeling of proteins by precursor ion scanning liquid chromatography/tandem mass spectrometry of derivatized amino acids applied to nuclear magnetic resonance studies. - Rapid Communications in Mass Spectrometry 26(10): 1165-1174.

[23] Leray, M., Yang, J. Y., Meyer, C. P., Mills, S. C. (2013): A new versatile primer set targeting a short fragment of the mitochondrial COI region for metabarcoding metazoan diversity: application for characterizing coral reef fish gut contents. - Frontiers in Zoology 10(1): 1-14.

[24] Li, G., Dong, H., Hou, W., Wang, S., Jiang, H., Yang, J., Wu, G. (2016): Temporal Succession of Ancient Phytoplankton Community in Qinghai Lake and Implication for Paleo-environmental Change. - Scientific Reports 6: 19769.

[25] Liao, K., Chen, W., Zhang, R., Zhou, H., Yan, X. (2017): qPCR analysis of bivalve larvae feeding preferences when grazing on mixed microalgal diets. - Plos One 12(6): $\mathrm{e} 0180730$.

[26] Manoylov, K. M. (2014): Taxonomic identification of algae (morphological and molecular): species concepts, methodologies, and their implications for ecological bioassessment. - Journal of Phycology 50(3): 409-424.

[27] Mao, Y., Lin, F., Fang, J., Fang, J., Li, J., Du, M. (2019): Bivalve Production in China. In: Smaal, A., Ferreira, J., Grant, J., Petersen, J., Strand, Ø. (eds.) Goods and Services of Marine Bivalves. Springer, Cham.

[28] Marquardt, J., Palinska, K. A. (2007): Genotypic and phenotypic diversity of cyanobacteria assigned to the genus Phormidium (Oscillatoriales) from different habitats and geographical sites. - Archives of Microbiology 187(5): 397-413.

[29] Møhlenberg, F., Riisgård, H. U. (1978): Efficiency of particle retention in 13 species of suspension feeding bivalves. - Ophelia 17: 239-246.

[30] Muller-Feuga, A., Moal, J., Kaas, R. (2003): The Microalgae of Aquaculture. - In: Stottrup, J. G., McEvoy, L. A. (eds.) Live Feeds in Marine Aquaculture. Blackwell Science, Oxford, pp. 206-252.

[31] Murphy, A. E., Anderson, I. C., Smyth, A. R., Song, B., Luckenbach, M. W. (2016): Microbial nitrogen processing in hard clam (Mercenaria mercenaria) aquaculture sediments: the relative importance of denitrification and dissimilatory nitrate reduction to ammonium (DNRA). - Limnology and Oceanography 61(5): 1589-1604.

[32] Nejstgaard, J. C., Frischer, M. E., Simonelli, P., Troedsson, C., Brakel, M., Adiyaman, F., Sazhin, A. F., Artigas, L. F. (2008): Quantitative PCR to estimate copepod feeding. Marine Biology 153(4): 565-577.

[33] Nelson, T. C. (1927): The mechanism of feeding in the oyster. - Proceedings of the Society for Experimental Biology and Medicine 21: 166-168.

[34] Nelson, T. C. (1947): Some contributions from the land in determining conditions of life in the sea. - Ecological Monographs 17: 337-346. 
[35] Newell, R. I. (2004): Ecosystem influences of natural and cultivated populations of suspension-feeding bivalve molluscs: a review. - Journal of Shellfish Research 23(1): 5162.

[36] Newell, R. I. E., Ott, J. A. (1999): Macrobenthic Communities and Eutrophication. - In: Malone, T. C., Smadlaka, N. A., Malej, A., Harding, L. W. Jr. (eds.) Ecosystems at the Land-Sea Margin: Drainage Basin to Coastal Sea. Coastal and Estuarine Comparisons series. American Geophysical Union, Washington, DC.

[37] Owen, G., Mccrae, J. M. (1976): Further studies on the latero-frontal tracts of bivalves. Proceedings of the Royal Society of London 194(1117): 527-544.

[38] Pales Espinosa, E., Cerrato, R. M., Wikfors, G. H., Allam, B. (2016): Modeling food choice in the two suspension-feeding bivalves, Crassostrea virginica and Mytilus edulis. - Marine Biology 163(2): 1-13.

[39] Puig, S., Videla, F., Cona, M. I., Monge, A. S. (2001): Use of food availability by guanacos (Lama guanicoe) and livestock in Northern Patagonia (Mendoza, Argentina). Journal of Arid Environments 47: 291-308.

[40] Qiao, L., Chang, Z., Li, J., Chen, Z., Yang, L., Luo, Q. (2019): Phytoplankton community structure and diversity in the indoor industrial aquaculture system for Litopenaeus vannamei revealed by high-throughput sequencing and morphological identification. Aquaculture Research 50: 2563-2576.

[41] Ribelin, B. W., Collier, A. (1977): Studies on the gill ciliation of the American oyster Crassostrea virginica (gmelin). - Journal of Morphology 151(3): 439-449.

[42] Riisgård, H. U. (1988): Efficiency of particle retention and filtration rate in 6 species of northeast American bivalves. - Marine Ecology Progress Series 45(3): 217-223.

[43] Rosa, M., Ward, J. E., Shumway, S. E., Wikfors, G. H., Pales-Espinosa, E., Allam, B. (2013): Effects of particle surface properties on feeding selectivity in the eastern oyster Crassostrea virginica and the blue mussel Mytilus edulis. - Journal of Experimental Marine Biology \& Ecology 446: 320-327.

[44] Rosa, M., Ward, J. E., Ouvrard, M., Holohan, B. A., Espinosa, E. P., Shumway, S. E., Allam, B. (2015): Examining the physiological plasticity of particle capture by the blue mussel, Mytilus edulis (L.): confounding factors and potential artifacts with studies utilizing natural seston. - Journal of Experimental Marine Biology and Ecology 473: 207217.

[45] Rosa, M., Ward, J. E., Shumway, S. E. (2018): Selective capture and ingestion of particles by suspension-feeding bivalve molluscs: a review. - Journal of Shellfish Research 37(4): 727-746.

[46] Sautour, B., Artigas, L. F., Delmas, D., Herbland, A., Laborde, P. (2000): Grazing impact of micro- and mesozooplankton during a spring situation in coastal waters off the Gironde estuary. - Journal of Plankton Research 22(3): 531-552.

[47] Schmidt, K., Atkinson, A., Stübing, D., Mcclelland, J. W., Montoya, J. P., Voss, M. (2003): Trophic relationships among Southern Ocean copepods and krill: some uses and limitations of a stable isotope approach. - Limnology and Oceanography 48(1): 277-289.

[48] Sherwood, A. R., Presting, G. G. (2007): Universal primers amplify a 23S rDNA plastid marker in eukaryotic algae and cyanobacteria. - Journal of Phycology 43(3): 605-608.

[49] Shumway, S. E., Cucci, T. L., Newell, R. C., Selvin, R., Guillard, R. R. L., Yentsch, C. M. (1985): Flow cytometry: a new method for characterization of differential ingestion, digestion and egestion by suspension feeders. - Marine Ecology Progress Series 24: 201204.

[50] Shumway, S. E., Cucci, T. L., Lesser, M. P., Bourne, N., Bunting, B. (1997): Particle clearance and selection in three species of juvenile scallops. - Aquaculture International 5(1): 89-99.

[51] Smyth, A. R., Geraldi, N. R., Piehler, M. F. (2013): Oyster-mediated benthic-pelagic coupling modifies nitrogen pools and processes. - Marine Ecology Progress Series 493: 23-30. 
[52] Sonier, R., Filgueira, R., Guyondet, T., Olivier, F., Meziane, T., Starr, M., LeBlanc, A. R., Comeau, L. A. (2016): Picoplankton contribution to Mytilus edulis growth in an intense culture environment. - Marine Biology 163: 73-85.

[53] Strauss, R. E. (1979): Reliability Estimates for Ivlev's Electivity Index, the Forage Ratio, and a Proposed Linear Index of Food Selection. - Transactions of the American Fisheries Society 108(4): 344-352.

[54] Strøhmeier, T., Strand, Ø., Alunno-Bruscia, M., Duinker, A., Cranford, P. J. (2012): Variability in particle retention efficiency by the mussel Mytilus edulis. - Journal of Experimental Marine Biology and Ecology 412: 96-102.

[55] Su, M., Liu, H., Liang, X., Gui, L., Zhang, J. (2018): Dietary analysis of marine fish species: enhancing the detection of prey-specific DNA sequences via high-throughput sequencing using blocking primers. - Estuaries and Coasts 41(2): 1-12.

[56] Tang, B., Liu, B., Wang, G., Tao, Z., Xiang, J. (2006): Effects of various algal diets and starvation on larval growth and survival of Meretrix meretrix. - Aquaculture 254(1-4): 526-533.

[57] Tawong, W. (2017): Diversity of the potential 2-methylisoborneol-producing genotypes in Thai strains of Planktothricoides (cyanobacteria). - Brazilian Archives of Biology and Technology 60: e17160567.

[58] Thajuddin, N., Subramanian, G. (2005): Cyanobacterial biodiversity and potential applications in biotechnology. - Current Science 89(1): 47-57.

[59] Ward, J. E., Shumway, S. E. (2004): Separating the grain from the chaff: particle selection in 720 suspension- and deposit-feeding bivalves. - Journal of Experimental Marine Biology and Ecology 300: 83-130.

[60] Wujek, D. E. (1979): Intracellular bacteria in the blue-green alga Pleurocapsa minor. Transactions of the American Microscopical Society 98(1): 143-145.

[61] Yeh, H. D., Questel, J. M., Maas, K. R., Bucklin, A. (2020): Metabarcoding analysis of regional variation in gut contents of the copepod Calanus finmarchicus in the North Atlantic Ocean. - Deep Sea Research Part II Topical Studies in Oceanography 180: 104738. 